Check for updates

Cite this: RSC Adv., 2017, 7, 54379

Received 15th September 2017 Accepted 17th November 2017

DOI: $10.1039 / c 7 r a 10242 a$

rsc.li/rsc-advances

\section{Preparation, characterization and antitumor activity evaluation of silibinin nanoparticles for oral delivery through liquid antisolvent precipitation}

\author{
Weiwei Wu, ${ }^{\text {a }}$ Yuangang Zu, ${ }^{\mathrm{b}}$ Lingling Wang, ${ }^{\mathrm{b}}$ Li Wang, ${ }^{\mathrm{b}}$ Yuanyuan Li, ${ }^{\mathrm{b}}$ Yanjie Liu, \\ Mingfang $\mathrm{Wu}^{\mathrm{b}}$ Xiuhua Zhao (D)*b and Xinxin Zhang ${ }^{\star a}$
}

Silibinin (SLB) is reported to possess multiple biological activities. However, due to its poor water solubility and poor absorption after oral administration, its clinical therapeutic effects have been limited. Thus, an experiment is designed to prepare SLB nanoparticles by the liquid antisolvent precipitation (LAP) technique to improve its solubility and bioavailability. Firstly, we applied single-factor experiments to investigate the effects of various factors on the mean particle size (MPS) of SLB nanoparticles in the LAP process, and the optimal conditions obtained were: HPMC concentration $3 \mathrm{mg} \mathrm{mL}^{-1}$, precipitation temperature $55{ }^{\circ} \mathrm{C}$, SLB concentration $35 \mathrm{mg} \mathrm{mL}^{-1}$, antisolvent/solvent volume ratio 10, dropping speed $1 \mathrm{~mL} \mathrm{~min}{ }^{-1}$, stirring speed $800 \mathrm{rpm}$ and stirring time $5 \mathrm{~min}$. A SLB nanosuspension with a MPS of $132.3 \mathrm{~nm}$ was obtained under the optimum conditions. The SLB nanoparticles were obtained by the freeze-drying method, and characterized using various analytical techniques such as SEM, FTIR, XRD DSC, and TG. The experimental data revealed that SLB nanoparticles were transformed into an amorphous form without changing the chemical structure, and had a higher solubility, and were about $36.9 \mathrm{mg} \mathrm{mL}^{-1}$ (free SLB was about $0.09 \mathrm{mg} \mathrm{mL}^{-1}$ ) in artificial gastric juice (AGJ) and about $59.71 \mathrm{mg} \mathrm{mL}^{-1}$ (free SLB was about $0.03 \mathrm{mg} \mathrm{mL}^{-1}$ ) in artificial intestinal juice (AIJ). The dissolution rate of SLB nanoparticles was also obviously higher than that of free SLB, and was about 48.2 times and 153.8 times that of free SLB in AGJ and in AIJ. Furthermore, the results of a bioavailability study in rats showed that the $C_{\max }$ value of SLB nanoparticles ( $398.580 \mathrm{ng} \mathrm{mL}{ }^{-1}$ ) was apparently higher than that of free SLB $\left(26.070 \mathrm{ng} \mathrm{mL}^{-1}\right)$, and the AUC $(0 \rightarrow t)$ value of SLB nanoparticles (965.666 $\mathrm{ng} \mathrm{mL}^{-1} \mathrm{~h}^{-1}$ ) was about 6.48 times greater than that of free SLB (149.124 $\mathrm{ng} \mathrm{mL}^{-1} \mathrm{~h}^{-1}$ ), so the SLB nanoparticles had a higher bioavailability than free SLB. The inhibitory effect of SLB nanoparticles on HepG2 cells was also higher by lower IC50 than that of free SLB. Taken together, the present study suggests that the SLB nanoparticles can become a new oral drug formulation with high bioavailability and produce a better response for its clinical applications.

\section{Introduction}

Silibinin (SLB, Fig. 1), a chemically defined plant-based drug, is the most important biologically active component of the silymarin complex, derived from seeds of the milk thistle plant, ${ }^{\mathbf{1 - 3}}$ and is composed of two diastereoisomers (silybin $\mathrm{A}$ and silybin B). ${ }^{4}$ Customarily, it is used extensively for treating liver diseases such as hepatitis, liver cirrhosis, and alcoholic liver diseases. ${ }^{5}$ Recent studies also found that SLB has an inhibitory effect on various cancer types such as liver cancer, prostate

${ }^{a}$ Key Laboratory of Saline-alkali Vegetation Ecology Restoration in Oil Field (SAVER), Ministry of Education, Alkali Soil Natural Environmental Science Center (ASNESC), Northeast Forestry University, Harbin Hexing Road, Harbin 150040, China. E-mail: 17381924@qq.com

${ }^{b}$ Key Laboratory of Forest Plant Ecology, Northeast Forestry University, Ministry of Education, Harbin 150040, Heilongjiang, China.E-mail: xiuhuazhao@nefu.edu.cn; Fax: +86-451-82102082; Tel: +86-451-82191517 cancer, colon cancer, breast cancer, skin cancer, lung cancer ${ }^{\mathbf{4}, 6,7}$ and so on, generating more and more extensive attention at home and abroad. Unfortunately, SLB is poorly absorbed with low bioavailability owing to poor water solubility in the human body, thereby severely limiting its clinical applications and<smiles>COc1cc([C@H]2Oc3cc([C@@H]4Oc5cc(O)cc(O)c5C(=O)[C@H]4O)ccc3O[C@@H]2CO)ccc1O</smiles>

Fig. 1 Chemical structure of silibinin. 
therapeutic efficiency. Therefore, the development of new pharmaceutical formulations that increase its solubility remains a subject of great importance.

Solubility of drugs is related to specific surface area; with decreasing particle size of drugs, the contact area between drugs and media can increase, thereby resulting in the improvement of the solubility and dissolution rate of drugs. ${ }^{8}$ In the past few years, many studies on bioavailability enhancement of silibinin set their aims at preparing nanoparticles by means of nanonization and take advantage of the large specific surface areas afforded by nanoparticles to improve its solubility and bioavailability, such as solid lipid nanoparticles, ${ }^{3}$ polymer nanoparticles, ${ }^{6,9}$ porous silica nanoparticles, ${ }^{\mathbf{1 0}}$ silibinin loaded $\mathrm{pH}$-SNEDDS emulsions ${ }^{\mathbf{1 1}}$ and so on. These nanoformulation strategies generally need a large number of carrier materials, or a combination of several materials to achieve better results, which is not only a waste of materials, but also increase production costs. In addition, it has also been reported that SLB crystals are prepared by the supercritical antisolvent technology, ${ }^{12}$ but this technique actually exists many problems including large equipment investment, wasted energy and lower productivity ${ }^{\mathbf{1 3 4}}$ and the SLB crystals obtained are in micron scale. Recently, the liquid antisolvent precipitation technique is a kind of promising bottom-up method to prepare nanoparticles/microparticles of poorly water-soluble drugs, and has some advantages including its process is relatively simple, easy to operate, lower cost, high yield, and has the potential to be applied in the pharmaceutical industry. ${ }^{15,16}$ This technique has been successfully used to prepare several drugs, such as genipin,,$^{13}$ rifampicin, ${ }^{17}$ trans-resveratrol, ${ }^{18}$ and taxifolin ${ }^{19}$ and so on. However, there have been no reports on the preparation of SLB nanoparticles by the liquid antisolvent precipitation (LAP) technique so far.

The LAP method provides an attractive option for drug nanoparticle formation at moderate temperature and pressure with no requirement of expensive equipment. ${ }^{20}$ Hence in the present study, the SLB nanoparticles were prepared by the LAP method. The different experimental factors on particle size were optimized through the single-factor experiment. The SLB nanoparticles obtained under the optimal conditions were characterized by various analytical techniques such as scanning electron microscopy (SEM), Fourier transform infrared spectroscopy (FTIR), X-ray diffraction (XRD), differential scanning calorimetry (DSC), and thermo gravimetric (TG). Furthermore, the saturation solubility, the release patterns in vitro and in vivo of SLB nanoparticles and antitumor activity were studied and investigated. In addition, the solvent residue test were also studied and analyzed in the present work.

\section{Materials and methods}

\subsection{Materials}

Silibinin (SLB, purity $=98 \%$ ) was purchased from Baoji Haoxiang Biotechnology Co., Ltd.; hydroxy-propyl-methyl-cellulose

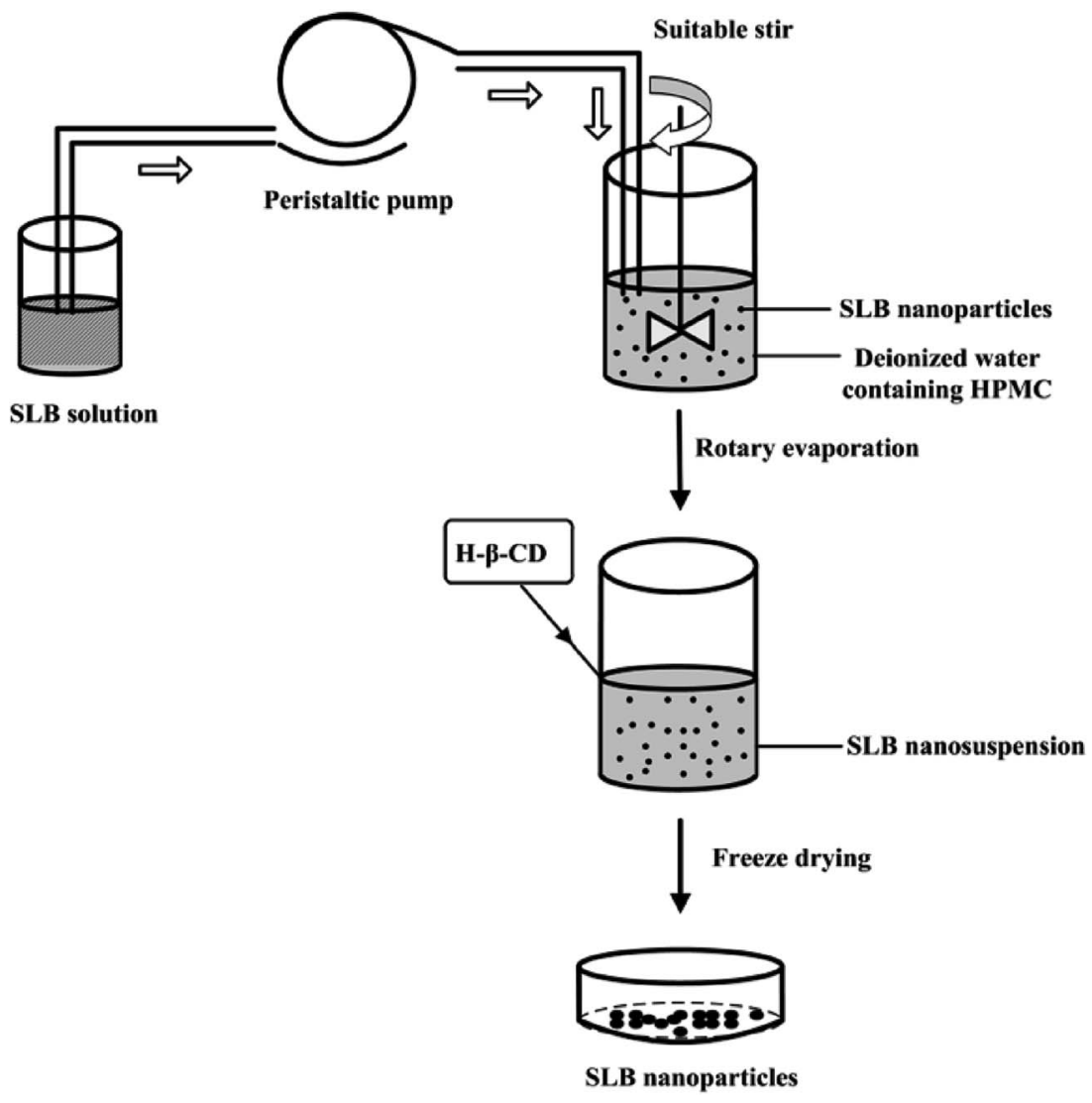

Fig. 2 Diagram of the experimental processes to prepare the SLB nanoparticles. 
Table 1 The factors and levels of the single factor design ${ }^{a}$

\begin{tabular}{|c|c|c|c|c|c|c|c|}
\hline \multirow[b]{3}{*}{ Levels } & \multicolumn{7}{|l|}{ Factor } \\
\hline & \multirow{2}{*}{$\begin{array}{l}\mathrm{A} \\
\text { HPMC } \\
\text { concentration } \\
\left(\mathrm{mg} \mathrm{mL} \mathrm{m}^{-1}\right)\end{array}$} & \multirow{2}{*}{$\begin{array}{l}\mathrm{B} \\
\text { Precipitation } \\
\text { temperature } \\
\left({ }^{\circ} \mathrm{C}\right)\end{array}$} & \multirow{2}{*}{$\begin{array}{l}\mathrm{C} \\
\text { SLB } \\
\text { concentration } \\
\left(\mathrm{mg} \mathrm{mL} \mathrm{mL}^{-1}\right)\end{array}$} & \multirow{2}{*}{$\begin{array}{l}\mathrm{D} \\
\text { Antisolvent/ } \\
\text { solvent volume } \\
\text { ratio }(\mathrm{v} / \mathrm{v})\end{array}$} & \multirow{2}{*}{ 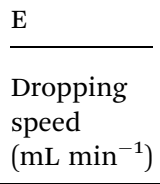 } & \multirow{2}{*}{$\begin{array}{l}\text { F } \\
\text { Stirring } \\
\text { speed } \\
\text { (rpm) }\end{array}$} & \multirow{2}{*}{$\begin{array}{l}\mathrm{G} \\
\text { Stirring } \\
\text { time } \\
\text { (min) }\end{array}$} \\
\hline & & & & & & & \\
\hline 1 & 1 & 15 & 10 & 5 & 1 & 400 & 3 \\
\hline 2 & 2 & 25 & 15 & 10 & 2 & 800 & 5 \\
\hline 3 & 3 & 35 & 20 & 15 & 3 & 1200 & 10 \\
\hline 4 & 4 & 45 & 25 & 20 & 4 & 1600 & 15 \\
\hline 5 & 5 & 55 & 30 & 25 & 5 & 2000 & 20 \\
\hline 6 & & & 35 & 30 & & & 30 \\
\hline 7 & & & 40 & & & & 45 \\
\hline 8 & & & & & & & 60 \\
\hline
\end{tabular}

(HPMC, viscosity $\sim 15 \mathrm{mPa}$ s) was purchased from Aladdin, 2hydroxypropyl- $\beta$-cyclodextrin (HP- $\beta$-CD), ethanol, methanol and glacial acetic acid were obtained from J\&K Scientific Ltd. (Beijing, China). MTT (3-(4,5-dimethylthiazol-2-yl)-2,5-diphenyl- $2 H$ tetrazolium bromide; 98\% purity) was supplied by SigmaAldrich. Deionized water was obtained by Hitech-K flow water purification system (Hitech Instruments Co., Ltd., Shanghai, China).

\subsection{Preparation of SLB nanoparticles}

In order to prepare the SLB nanoparticles, a certain amount of SLB was accurately weighed and dissolved in ethanol at $60^{\circ} \mathrm{C}$ to ensure that all the drugs were in the organic phase. Then, the SLB solution obtained was injected into the aqueous solution containing HPMC drop-wise at constant temperature under magnetic stirring to precipitate nanoparticles. After some time, the ethanol in the nanosuspension was removed from the nanosuspension using a rotary evaporator R201BL (SENCO, Shanghai, China) at $55^{\circ} \mathrm{C}$, and then a certain amount of HP- $\beta$-CD were added into the nanosuspension and mixed evenly, finally the SLB nanoparticles was obtained by the lyophilizer at $-68{ }^{\circ} \mathrm{C}$ for $64 \mathrm{~h}$. The preparation processes are illustrated in Fig. 2.

\subsection{Optimization of the preparation process of SLB nanoparticles}

In the LAP processes, several experimental variables, such as precipitation temperature, drugs concentration, type of surfactant and adding amount, antisolvent/solvent volume ratio, dropping speed, and stirring speed and time can affect the MPS of drug nanoparticles. Therefore, in order to obtain the optimal operating conditions, the single-factor experiment was operated to investigate the effects of various factors on the MPS of SLB nanoparticles in the LAP process. Through preliminary experiments, the value of each factor was preliminarily confirmed, as follows: the precipitation temperature was studied at $15-55{ }^{\circ} \mathrm{C}$. The HPMC was selected as a surfactant and the HPMC concentration was studied at 1-5 $\mathrm{mg} \mathrm{mL}^{-1}$. The SLB concentration was studied at $10-40 \mathrm{mg} \mathrm{mL}^{-1}$. The antisolvent/ solvent volume ratio was studied at 5-30. The dropping speed was studied at $1-5 \mathrm{~mL} \mathrm{~min}^{-1}$. The stirring speed and the stirring time were studied at 400-2000 rpm and 3-60 min, respectively. Finally, the optimal conditions of each factor were obtained according to the smallest MPS of each factor. The MPS was measured by dynamic laser light scattering technique (ZetaPALS, Brookhaven, USA). Each experiment was repeated at least three times. Factors investigated and their levels in this study were summarized in Table 1.

When the SLB nanosuspension was obtained under the optimal conditions, a certain amount of HP- $\beta$-CD as a cryoprotectant were added into the SLB nanosuspension and mixed evenly, finally the SLB nanoparticles was obtained by the lyophilizer at $-68{ }^{\circ} \mathrm{C}$ for $64 \mathrm{~h}$. In this paper, the HP- $\beta$-CD was selected as a cryoprotectant by the preliminary experiments, and it can effectively coat on the surface of the drug nanoparticles in the freeze-drying process to prevent the aggregation of the nanoparticles, and can also improve the solubility of SLB. The SLB-HP- $\beta$-CDs $(1: 0,1: 3,1: 4,1: 5,1: 6,1: 7,1: 8$, $\mathrm{mg} \mathrm{mg}^{-1}$ ) nanoparticles were prepared and their solubility was detected by HPLC method. By comparing their solubility, the optimal ratio of SLB to HP- $\beta$-CD was selected out. The experiment was conducted in triplicate.

\subsection{Morphology observation}

Morphological structures of free SLB, SLB nanoparticles were obtained using a scanning electron microscope (Quanta 200, FEI; The Netherlands). In order to observe the morphology of SLB nanoparticles, the SLB nanoparticles lyophilized powder was washed 3-4 times with deionized water by centrifugation to remove the HP- $\beta$-CD. The nanoparticles obtained were redispersed in deionized water and then dropped on the foil and dried. The samples were stored at a desiccator, subsequently they were mounted on aluminum stubs with double sided carbon tape and coated with a thin conductive gold, and then the morphology and size of the samples were observed. 


\subsection{Solid state characterization}

2.5.1. FTIR. FTIR measurements were performed by FTIR spectroscopy (Shimadzu Corporation, Japan) in the wavenumber range of $400-4000 \mathrm{~cm}^{-1}$ using a resolution of $2 \mathrm{~cm}^{-1}$. The samples were diluted with $\mathrm{KBr}$ mixing powder at $1 \%$ and then pressed into transparent slices for analysis.

2.5.2. XRD. XRD measurements were performed on an X-ray diffractometer (Philips, Xper t-Pro; The Netherlands). The voltage and current using $\mathrm{Cu} \mathrm{K} \alpha$ radiation were $35 \mathrm{kV}$ and $40 \mathrm{~mA}$, respectively. Samples were placed in a glass sample holder and scanned from $5^{\circ}$ to $60^{\circ}$ of $2 \theta$ with a step size of $0.02^{\circ}$ with a scan rate of $4^{\circ} \mathrm{min}^{-1}$.

2.5.3. DSC. Thermal properties of the samples were determined by DSC (TA instruments, model, DSC 204). The samples were hermetically sealed in solid pans and heated from 40 to $300{ }^{\circ} \mathrm{C}$ at a heating rate of $10{ }^{\circ} \mathrm{C} \mathrm{min}^{-1}$.

2.5.4. TG. TGA was performed using a thermogravimetric analyzer (TGA, Diamond TG/DTA PerkinElmer, USA). The samples (2-3 mg) were heated in alumina crucible in nitrogen atmosphere, and the temperature range was from $40{ }^{\circ} \mathrm{C}$ to $600{ }^{\circ} \mathrm{C}$ and the heating rate was $10{ }^{\circ} \mathrm{C} \mathrm{min}^{-1}$.

\subsection{Saturation solubility and dissolution study}

2.6.1. HPLC. The SLB concentration was measured by the high performance liquid chromatograph of WATERS (Waters Corporation, Milford, MA, USA) with a Diamonsil $\mathrm{C}_{18}$ reversephase column (250 $\mathrm{mm} \times 4.6 \mathrm{~mm}, 5 \mu \mathrm{m}$, China). The mobile phase was a solution of glacial acetic acid (0.1\%)-methanol (52:48, v/v). The column was maintained at $30{ }^{\circ} \mathrm{C}$ and equilibrated for 60 min with the analytical mobile phase before injection. The flow rate of the mobile phase was set at

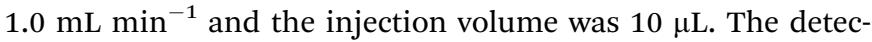
tion was performed at $287 \mathrm{~nm}$.

2.6.2. Saturation solubility measurement. Saturation solubility of free SLB, SLB nanoparticles, physical mixture of SLB with auxiliary materials was detected by HPLC method. Procedure was as follows: excessive and identical SLB amount of each sample were weighed and separately placed into three vials containing $2 \mathrm{~mL}$ release medium. AGJ ( $\mathrm{pH} 1.2$ ) containing $0.4 \%$ Tween-80 and AIJ ( $\mathrm{pH}$ 6.8) were selected as the release medium. All the samples were placed in a shaker water bath agitated at $100 \mathrm{rpm}$ and maintained at $37^{\circ} \mathrm{C}$. After $48 \mathrm{~h}$, the suspension was centrifuged at $12000 \mathrm{rpm}$ for $10 \mathrm{~min}$ by a centrifugal and the supernatant was diluted suitably with methanol and analyzed by the HPLC system. The analysis conditions were described in Section 2.6.1. The experiment was conducted in triplicate.

2.6.3. Dissolution study. Dissolution studies were carried out in AGJ ( $\mathrm{pH}$ 1.2) with $0.4 \%$ Tween-80 and AIJ ( $\mathrm{pH} 6.8$ ), respectively. The rotation speed of paddle and the bath temperature were set to be $100 \mathrm{rpm}$ and $37{ }^{\circ} \mathrm{C}$, respectively. $200 \mathrm{mg}$ of free SLB, $1.6 \mathrm{~g}$ of SLB nanoparticles equating with $200 \mathrm{mg}$ of SLB and physical mixture of free SLB (200 mg) with auxiliary materials were dispersed into in dialysis bag with the release medium $(5 \mathrm{~mL})$, respectively, and then the end-sealed dialysis bags were placed in the vessel containing $200 \mathrm{~mL}$ release medium. At 0.08, 0.17, 0.25, 0.33, 0.5, 1, 1.5, 2, 4, 6, 8, 12 and $24 \mathrm{~h}, 1 \mathrm{~mL}$ aliquots of release medium was withdrawn and same amount replaced by fresh medium. The collected sample was centrifuged at $10000 \mathrm{rpm}$ for $10 \mathrm{~min}$ by the centrifugation and then was diluted suitably and analyzed by the HPLC system. The detection conditions were described in the Section 2.6.1. The experiment was conducted in triplicate.

\subsection{Oral bioavailability study in rats}

Twelve Sprague-Dawley rats, weighing about 200-250 g, were randomly divided into two groups and had fasted overnight before the drug administration. However, the rats were provided with free access to water throughout the study. All animal procedures were performed in accordance with the Guidelines for Care and Use of Laboratory Animals of Harbin Medical University and approved by the Ethics Committee of the Harbin Medical University. The drug was administered as an oral dose (50 $\left.\mathrm{mg} \mathrm{kg}^{-1}\right)$ to two groups of rats $(n=6$ in each group). Two groups of rats received free SLB and SLB nanoparticles, respectively. Blood samples were taken from the retroorbital plexus at $0.08,0.17,0.25,0.33,0.5,1 \mathrm{~h}, 1.5,2,4,6,8,12$ and $24 \mathrm{~h}$ after oral administration. The samples collected were centrifuged (10 $\mathrm{min}, 3000 \mathrm{rpm}$ ) and the plasma samples were kept frozen at $-40{ }^{\circ} \mathrm{C}$ until analysis.

For the extraction of SLB from rat plasma, the plasma of $0.2 \mathrm{~mL}$ was transferred to $2 \mathrm{~mL}$ centrifuge tube containing $0.4 \mathrm{~mL}$ of acetonitrile. The mixture was followed by vortex agitation for $3 \mathrm{~min}$ and mixed evenly, then was ultrasonically treated for $30 \mathrm{~min}$ and centrifuged at $12000 \mathrm{rpm}$ for $10 \mathrm{~min}$. Finally, the supernate obtained was analyzed by the HPLC method.

\subsection{Antitumor activity evaluation}

Antitumor activity of SLB nanoparticles was investigated with MTT assay which evaluated metabolic activity of cells treated with the complexes. The human HCC cell line HepG2 was donated by Beina Chuanglian Biotechnology Research Institute (Beijing, China). The cells were cultured in Dulbecco's modified Eagle's medium, which was supplemented with $10 \%$ fetal bovine serum (FBS), $100 \mathrm{U} \mathrm{mL}^{-1}$ penicillin, and $100 \mathrm{mg} \mathrm{mL}^{-1}$ streptomycin at $37{ }^{\circ} \mathrm{C}$ in humidified atmosphere with $5 \% \mathrm{CO}_{2}$. Cells in the logarithmic phase were collected for experiments. Logarithmic-phase cells were digested and carefully prepared into uniform cell suspension. The cell suspension was seeded into 96-well plates and cultivated in a $5 \% \mathrm{CO}_{2}$ incubator at $37{ }^{\circ} \mathrm{C}$ for $24 \mathrm{~h}$. After cell adhesion on the culture, the samples containing free SLB and SLB nanoparticles with different SLB concentration (SLB: 1000.0, 500.0, 250.0, 125.0, 62.5, 31.25, 15.63 and $7.82 \mu \mathrm{g} \mathrm{mL} \mathrm{m}^{-1}$ ) were added in the plates. Each concentration was repeated six times. The samples of different SLB concentrations were dissolved by cell-culture medium and diluted appropriately. Following $48 \mathrm{~h}$ incubation, $10 \mu \mathrm{L}$ of $5 \mathrm{mg} \mathrm{mL} \mathrm{m}^{-1}$ MTT was added into each well and incubated for $4 \mathrm{~h}$. The supernatant was discarded, and $150 \mu \mathrm{L}$ of DMSO was added to the wells. The plate was placed on a horizontal oscillator to enhance the solvation of formazan crystals. Absorbance value 
(OD) was measured by using the enzyme mark analyzer instrument (detection wavelength of $490 \mathrm{~nm}$ and reference wavelength of $630 \mathrm{~nm}$ ) and compared with the blank. Tumor cell growth inhibition efficiency (\%) was calculated using (OD cost of contrastive group-OD cost of medicate group/OD cost of contrastive group) $\times 100$. This equation was also used to calculate the half maximal inhibitory concentration (IC50).

\subsection{GC measurement}

An Agilent 7890A gas chromatograph (Agilent Technologies, Palo Alto, CA, USA) was introduced to determine whether there was residual ethanol in SLB nanoparticles, equipping with a HP5 (5\% phenyl methyl siloxane) capillary column $(30.0 \mathrm{~m} \times 320$ $\mu \mathrm{m} \times 0.25 \mu \mathrm{m}$, nominal) and a G1540N-210 flame ionization detector. $10 \mathrm{mg}$ SLB nanoparticles were completely dissolved into $1 \mathrm{~mL}$ water, and then centrifuged for $10 \mathrm{~min}$ at $10000 \mathrm{rpm}$. The supernate obtained was analyzed by the GC system. GC analysis conditions of ethanol were as follows: initial temperature was kept at $40{ }^{\circ} \mathrm{C}$ for $6 \mathrm{~min}$, and then increased at the heating rate of $30^{\circ} \mathrm{C} \mathrm{min}^{-1}$ to $240^{\circ} \mathrm{C}$, and maintained for $4 \mathrm{~min}$. The injector and the detector temperatures were both set at $200{ }^{\circ} \mathrm{C}$. The makeup gas rate was $25 \mathrm{~mL} \mathrm{~min}{ }^{-1}$, and $2 \mu \mathrm{L}$ samples were injected manually in the GC. The rate of $\mathrm{H}_{2}$ and the rate of air were respectively 30 and $400 \mathrm{~mL} \mathrm{~min}^{-1}$. The split ratio was $20: 1$.

\section{Results and discussion}

\subsection{Optimization result}

This experiment applied the LAP technique to prepare SLB nanoparticles, thus improving the solubility and bioavailability of SLB. In order to obtain the optimal operating conditions, the single-factor experiment was applied to investigate the effects of various factors on the MPS of SLB nanoparticles in the LAP process. In each set of experiments, when one of the variables was modified and other variables were fixed, the effect of the different variables on MPS could be evaluated. Experimental results of the single factor experiment are shown in Fig. 3.

3.1.1. The HPMC concentration. Suitable surfactant can effectively adsorb on the surface of drugs, prevent the growth of particles and be beneficial to decrease the particle size of drugs, and help the dispersion stability of the particles in water. ${ }^{21,22}$ In this experiment, the HPMC was selected as a surfactant by the pre-experiments. When other factors were fixed, the effects of the HPMC concentration $\left(1,2,3,4\right.$ and $\left.5 \mathrm{mg} \mathrm{mL}^{-1}\right)$ on the MPS of SLB were investigated. As shown in Fig. 3a, with the HPMC concentration increasing from $1 \mathrm{mg} \mathrm{mL}^{-1}$ to $3 \mathrm{mg} \mathrm{mL}^{-1}$, the MPS was obviously decreased from $317.8 \mathrm{~nm}$ to $147.1 \mathrm{~nm}$, but when the HPMC concentration increased from $3 \mathrm{mg} \mathrm{mL}{ }^{-1}$ to $5 \mathrm{mg} \mathrm{mL}^{-1}$, the change of the MPS of SLB was unconspicuous. Moreover, the amount of pharmaceutical excipients should be as little as possible under the precondition of smaller particle size, thus the HPMC concentration $\left(3 \mathrm{mg} \mathrm{mL}^{-1}\right)$ was confirmed as the optimum condition.

3.1.2. The precipitation temperature. The precipitation temperature of the system is an important factor for the preparation of SLB nanoparticles by the LAP method. The effects of different precipitation temperature $(15,25,35,45$ and $55^{\circ} \mathrm{C}$ ) on the MPS of SLB were investigated. As shown in Fig. 3b, with increasing the precipitation temperature from 15 to $55^{\circ} \mathrm{C}$, the MPS of SLB decreased from 204.2 to $142.4 \mathrm{~nm}$. In addition, the system containing HPMC had a certain viscosity (HPMC, viscosity $\sim 15 \mathrm{mPa} \mathrm{s}$ ), and the viscosity of the system changed along with the temperature, thus affecting the particle size of drug particles. Through viscosity measurement, the viscosities of the system at different temperatures were $2.4208 \mathrm{cP}$ at $15^{\circ} \mathrm{C}$, $1.6252 \mathrm{cP}$ at $25{ }^{\circ} \mathrm{C}, 1.2761 \mathrm{cP}$ at $35^{\circ} \mathrm{C}, 1.0247 \mathrm{cP}$ at $45^{\circ} \mathrm{C}$ and $0.7763 \mathrm{cP}$ at $55{ }^{\circ} \mathrm{C}$, respectively. When the precipitation temperature was low, many larger drug particles generated, perhaps because low temperature led to a too high solution viscosity and then made the drug particles form a paste in the LAP process. However, with the increase of the precipitation temperature, the viscosity of the solution decreased, which was beneficial to the production of small drug particles. Therefore, the precipitation temperature $\left(55^{\circ} \mathrm{C}\right)$ was confirmed as the optimum condition.

3.1.3. The SLB concentration. The drug concentration of the system is another important factor for the preparation of SLB nanoparticles by the LAP method. The effects of different SLB concentration $\left(10,15,20,25,30,35\right.$ and $\left.40 \mathrm{mg} \mathrm{mL}^{-1}\right)$ on the MPS of SLB were investigated. As shown in Fig. 3c, with the concentration of SLB increasing from 10 to $35 \mathrm{mg} \mathrm{mL}^{-1}$, the MPS of SLB decreased from 179.2 to $129.1 \mathrm{~nm}$. However, when the drug concentration was higher than $35 \mathrm{mg} \mathrm{mL}^{-1}$, the MPS of SLB scarcely changed. Therefore, the increase of drug concentration led to the MPS of SLB decreasing. This might be because the increase in drug concentration will increase the supersaturation of the system, resulting in the nucleation rate of the crystal was greater than the growth rate, which was conducive to the formation of small particles. ${ }^{23}$ Moreover, when the drug concentration was equal or higher than $40 \mathrm{mg} \mathrm{mL}^{-1}$, it was difficult to completely dissolve SLB in ethanol. Therefore, from the overall consideration, the SLB concentration $\left(35 \mathrm{mg} \mathrm{mL}^{-1}\right)$ was selected as the optimum condition.

3.1.4. The antisolvent/solvent volume ratio. The effects of the antisolvent/solvent volume ratio $(5,10,15,20,25$ and 30) on the MPS of SLB were investigated, as shown in Fig. 3d. With the antisolvent/solvent volume ratio increasing from 5 to 10 , the MPS of SLB decreased from 251.4 to $133.6 \mathrm{~nm}$. When the volume ratio was 10, the MPS of SLB was the smallest at about $133.6 \mathrm{~nm}$. But when the antisolvent/solvent volume ratio was more than 10, the MPS of SLB began to increase and then almost unchanged. This may be because when the volume ratio increased from 5 to 10, the increase of the antisolvent ratio can increase the supersaturation of the system, which was conducive to the formation of small particles. ${ }^{24}$ However, when the volume ratio increased from 10 to 30 , the degree of supersaturation of the system was almost unchanged, thus resulting in the MPS of SLB change indistinctively. So the antisolvent/ solvent volume ratio (10) was selected as the optimum condition.

3.1.5. The dropping speed. The influences of dropping speed $\left(1,2,3,4\right.$ and $\left.5 \mathrm{~mL} \mathrm{~min}^{-1}\right)$ on the MPS of SLB were 

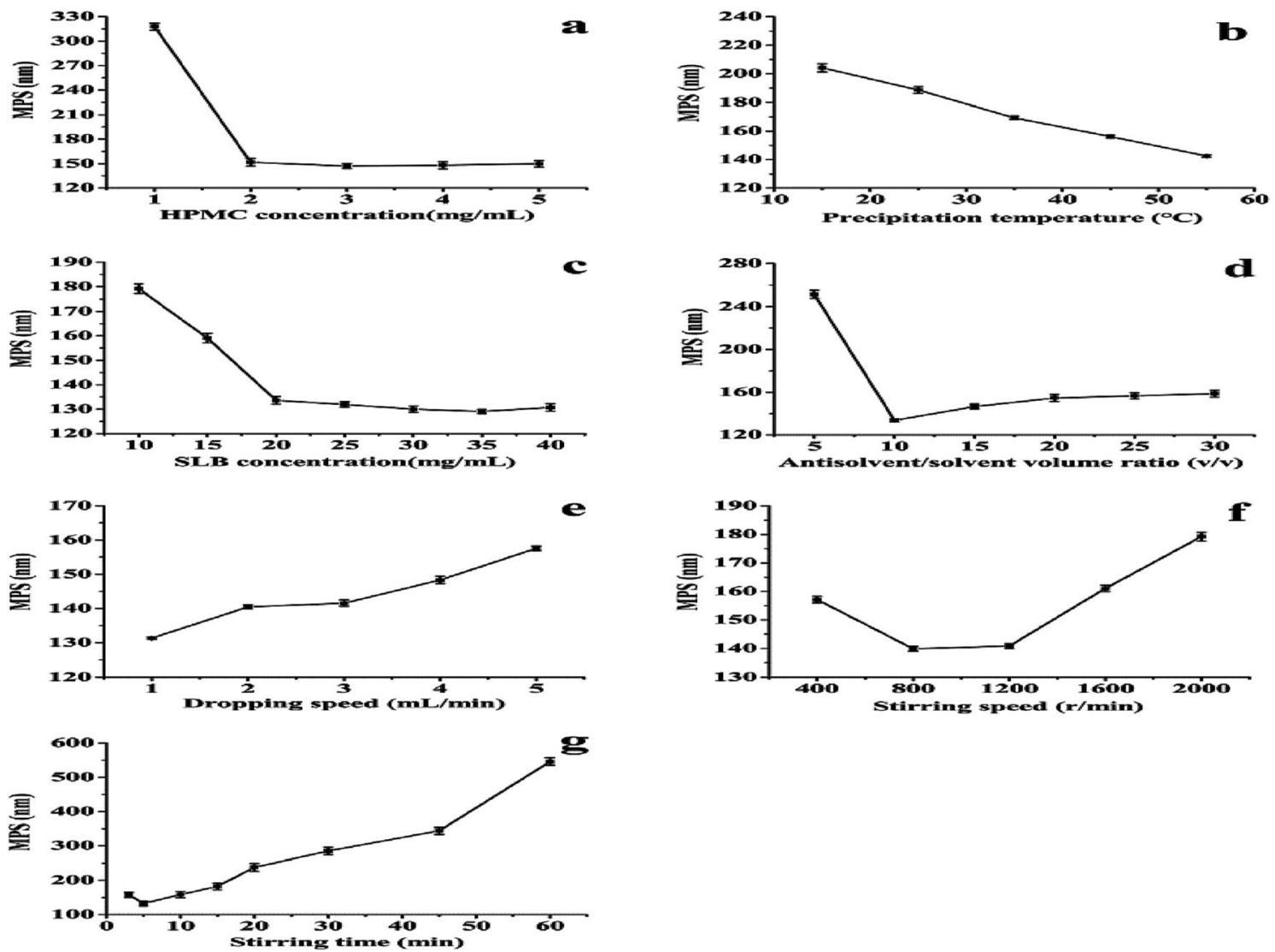

Fig. 3 The effect of each factor on the MPS of SLB nanoparticles. (a) HPMC concentration (SLB concentration: $30 \mathrm{mg} \mathrm{mL}^{-1}$; antisolvent/solvent volume ratio: 10; precipitation temperature: $55^{\circ} \mathrm{C}$; dropping speed: $1 \mathrm{~mL} \mathrm{~min}{ }^{-1}$; stirring speed: 800 rpm; stirring time: 5 min); (b) precipitation temperature (HPMC concentration: $3 \mathrm{mg} \mathrm{mL}^{-1}$; SLB concentration: $30 \mathrm{mg} \mathrm{mL}^{-1}$; antisolvent/solvent volume ratio: 10; dropping speed: $1 \mathrm{~mL} \mathrm{~min}{ }^{-1}$; stirring speed: $800 \mathrm{rpm}$; stirring time: $5 \mathrm{~min}$ ); (c) SLB concentration (HPMC concentration: $3 \mathrm{mg} \mathrm{mL}^{-1}$; precipitation temperature:

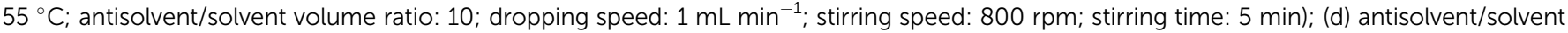
volume ratio (HPMC concentration: $3 \mathrm{mg} \mathrm{mL}^{-1}$; SLB concentration: $35 \mathrm{mg} \mathrm{mL}^{-1}$; precipitation temperature: $55^{\circ} \mathrm{C}$; dropping speed: $1 \mathrm{~mL} \mathrm{~min}^{-1}$; stirring speed: $800 \mathrm{rpm}$; stirring time: $5 \mathrm{~min}$ ); (e) dropping speed (HPMC concentration: $3 \mathrm{mg} \mathrm{mL}^{-1}$; SLB concentration: $35 \mathrm{mg} \mathrm{mL}^{-1}$; precipitation temperature: $55{ }^{\circ} \mathrm{C}$; antisolvent/solvent volume ratio: 10; stirring speed: $800 \mathrm{rpm}$; stirring time: $5 \mathrm{~min}$ ); (f) stirring speed (HPMC concentration: $3 \mathrm{mg} \mathrm{mL}^{-1}$; SLB concentration: $35 \mathrm{mg} \mathrm{mL}^{-1}$; precipitation temperature: $55^{\circ} \mathrm{C}$; antisolvent/solvent volume ratio: 10 ; dropping speed: $1 \mathrm{~mL} \mathrm{~min}{ }^{-1}$; stirring time: $5 \mathrm{~min}$ ); (g) stirring time (HPMC concentration: $3 \mathrm{mg} \mathrm{mL}^{-1}$; SLB concentration: $35 \mathrm{mg} \mathrm{mL}^{-1}$; precipitation temperature: $55^{\circ} \mathrm{C}$; antisolvent/solvent volume ratio: 10 ; dropping speed: $1 \mathrm{~mL} \mathrm{~min}^{-1}$; stirring speed: $800 \mathrm{rpm}$ ).

examined, as shown in Fig. 3e. As dropping speed increased from $1 \mathrm{~mL} \min ^{-1}$ to $5 \mathrm{~mL} \mathrm{~min}^{-1}$, the MPS of SLB increased from 131.3 to $157.6 \mathrm{~nm}$. The results illustrated that, when other conditions were fixed, the slow dropping speed was favorable for the particles to be fully dispersed and reduced collision and agglomeration between particles, was conducive for small particles formation. So the dropping speed $\left(1 \mathrm{~mL} \mathrm{~min}^{-1}\right)$ was selected as the optimum condition.

3.1.6. The stirring speed and the stirring time. The effects of different stirring speed and stirring time on the MPS of SLB were studied and shown in Fig. 3f and g. From the Fig. 3f, the MPS of SLB reduced from $157.1 \mathrm{~nm}$ to $139 \mathrm{~nm}$ with increasing the stirring speed from 400 to $800 \mathrm{rpm}$. And the MPS of SLB had no significant change within the range of $800-1200 \mathrm{rpm}$, however, when the stirring speed was higher than $1200 \mathrm{rpm}$, the MPS began to increase. In addition, when the stirring speed was maintained, as the stirring time increased from 3 to $60 \mathrm{~min}$, the particle size of SLB first decreased and then increased (Fig. 3g), when the stirring time was 5 min, the smallest MPS was obtained and was about $132.3 \mathrm{~nm}$. These results demonstrate that, the higher mixing speed or the longer stirring time may easily result in too much energy and destroy the relative balance of the system, led to agglomeration and growth of particles. Therefore, the stirring speed $(800 \mathrm{rpm})$ and the stirring time $(5 \mathrm{~min})$ were selected as the optimal conditions, respectively.

3.1.7. The amount of HP- $\beta$-CD. In this study, the HP- $\beta$-CD was selected as a cryoprotectant and it could effectively coat on the surface of the drug nanoparticles in the freeze-drying process to prevent the aggregation of the nanoparticles, and could also improve the solubility of SLB. Therefore, the SLB-HP$\beta$-CDs $\left(1: 0,1: 3,1: 4,1: 5,1: 6,1: 7,1: 8, \mathrm{mg} \mathrm{mg}^{-1}\right)$ nanoparticles were prepared and their solubility was detected by HPLC method. By comparing their solubility, the optimal ratio of SLB to HP- $\beta$-CD was selected out. The process of samples treatment was as follows: excessive and identical SLB amount of each sample were weighed and separately added into $2 \mathrm{~mL}$ 


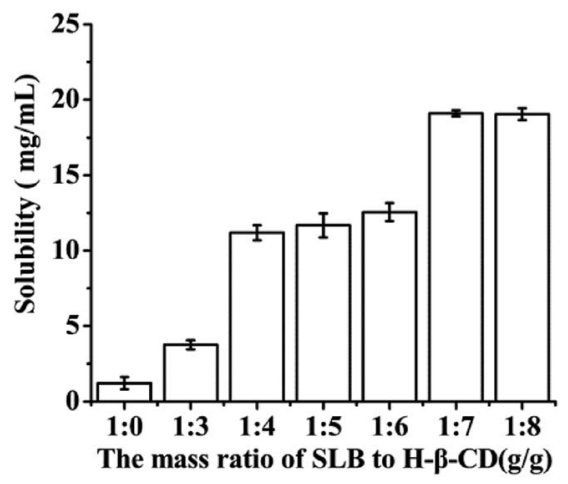

Fig. 4 The effect of HP- $\beta-C D$ amount on the solubility of SLB nanoparticles.

centrifuge tube containing $2 \mathrm{~mL}$ water, then all the samples was ultrasonically treated for $30 \mathrm{~min}$, then centrifuged at $12000 \mathrm{rpm}$ for $10 \mathrm{~min}$ by a centrifugal, the supernate obtained was diluted suitably and analyzed by the HPLC system. Experimental results were shown in Fig. 4, with increasing the amount of HP- $\beta-\mathrm{CD}$, the solubility of the corresponding nanoparticles was also increased. When the mass ratio of SLB to HP$\beta$-CD was $1: 7$, the solubility was the highest at about $19.09 \mathrm{mg} \mathrm{mL}{ }^{-1}$. But when the amount of HP- $\beta-\mathrm{CD}$ increased further, the solubility of the corresponding nanoparticles was almost unchanged. Consequently, the ratio of SLB to HP- $\beta-C D$ of $1 / 7$ was the optimal condition in this study.

Through the above analysis, the optimal conditions were: the HPMC concentration was $3 \mathrm{mg} \mathrm{mL} \mathrm{mL}^{-1}$. The SLB concentration was $35 \mathrm{mg} \mathrm{mL}{ }^{-1}$. The antisolvent/solvent volume ratio was 10 .
The dropping speed was $1 \mathrm{~mL} \mathrm{~min}^{-1}$. The stirring speed and the stirring time were $800 \mathrm{rpm}$ and $5 \mathrm{~min}$, respectively. SLB nanosuspension with a MPS of $132.3 \mathrm{~nm}$ was obtained under the optimum conditions. In addition, HP- $\beta$-CD was selected as cryoprotectant and the optimum ratio of SLB to HP- $\beta$-CD was $1: 7$. In the end, SLB nanoparticles were obtained by lyophilization and used for the following detections.

\subsection{SEM results}

Fig. 5 showed representative SEM images of free SLB, SLB nanoparticles. In Fig. 5a and b, the morphology of free SLB was irregular block, with the particle size varying from $2.49 \mu \mathrm{m}$ to $7.61 \mu \mathrm{m}$. However, the Fig. $5 \mathrm{c}$ and $\mathrm{d}$ was the surface of SLB observed in SLB nanoparticles lyophilized powder by SEM, and its morphology was spherical and smooth, with particle size distributed between 120 and $140 \mathrm{~nm}$, supporting the results of particle size of the SLB nanosuspension obtained under the optimum conditions. The results showed that the SLB nanoparticles maintained good morphology and particle size due to the presence of HP- $\beta$-CD in the freeze-drying process.

\subsection{FTIR analyses}

The FT-IR spectra of the samples including free SLB, SLB nanoparticles, physical mixture of SLB with excipients, HPMC and HP- $\beta$-CD were shown in Fig. 6 . Free SLB spectrum (curve a) showed characteristic peaks at 3452 (-OH stretching vibration), 1632 ( $\mathrm{C}=\mathrm{O}$ stretching), 1506-1468 (skeleton vibration of aromatic $\mathrm{C}=\mathrm{C}$ ring stretching), $1270 \mathrm{~cm}^{-1}$ (C-O-C stretching). The FT-IR spectrum of HP- $\beta$-CD (curve e) showed characteristic peaks at $3396\left(\mathrm{O}-\mathrm{H}\right.$ groups vibration), $2929\left(\mathrm{O}-\mathrm{CH}_{3}\right.$ groups
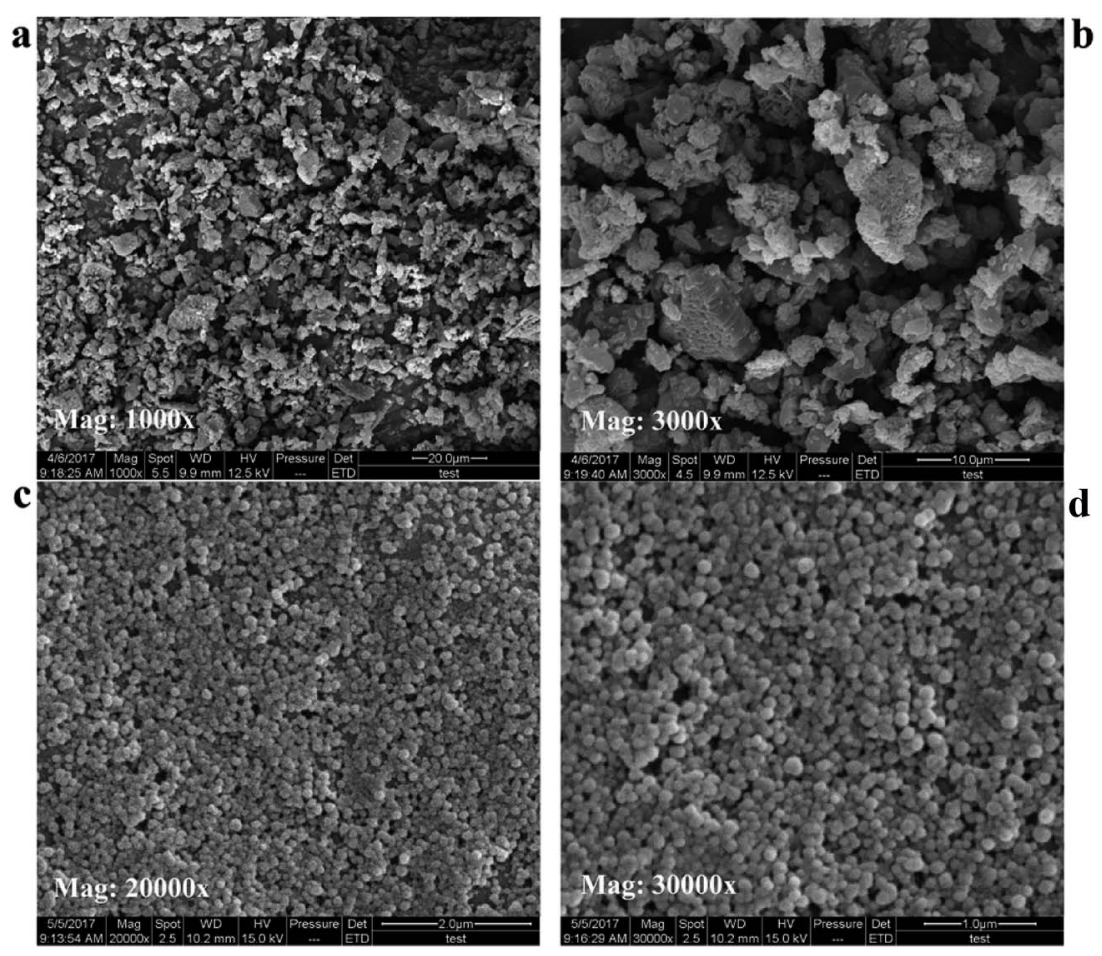

Fig. 5 SEM images of each sample. (a) and (b) free SLB; (c) and (d) SLB nanoparticles. 


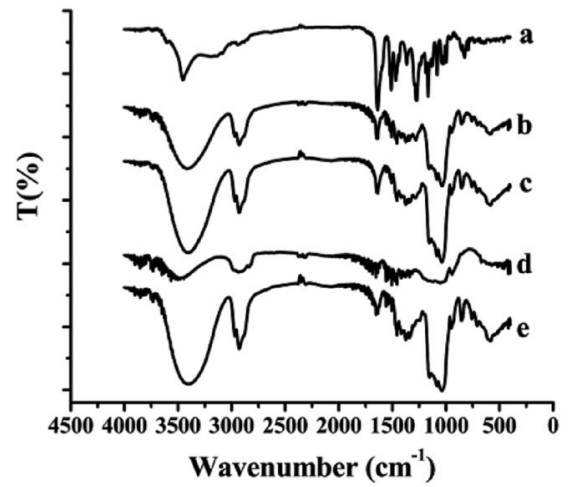

Fig. 6 FTIR spectra of each sample. (a) Free SLB; (b) SLB nanoparticles; (c) physical mixture of SLB with excipients; (d) HPMC; (e) HP- $\beta-C D$.

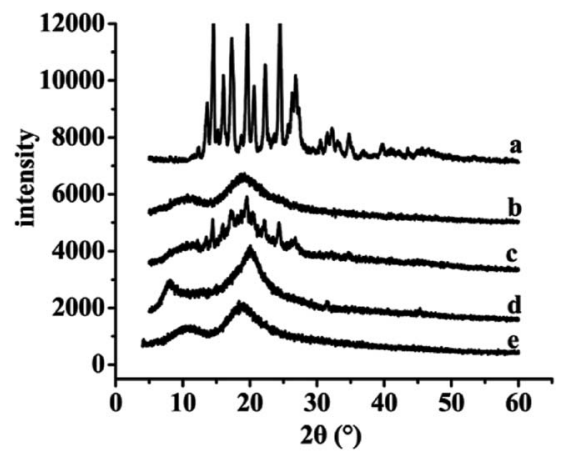

Fig. 7 XRD results of each sample. (a) Free SLB; (b) SLB nanoparticles; (c) physical mixture of SLB with excipients; (d) HPMC; (e) HP- $\beta-C D$.

vibration), 1151, 1083, and $1037 \mathrm{~cm}^{-1}$ (C-O groups vibration). However, the spectra of both physical mixture (curve c) and SLB nanoparticles (curve b) did not show any changes in peak position from the SLB and HP- $\beta$-CD spectra, but only some peaks of the SLB were covered in the spectrum of the SLB nanoparticles, which maybe because the HP- $\beta$-CD coated on the surface of the SLB.

\subsection{XRD and DSC analyses}

The results of XRD and DSC of the samples, including free SLB, SLB nanoparticles, physical mixture of SLB with excipients, HPMC and HP- $\beta$-CD were shown in Fig. 7 and 8. From the figure, free SLB (Fig. 7a) exhibited some intense crystalline peaks between $5^{\circ}$ and $60^{\circ}$, and its melting points (Fig. 8a) were about $155.6^{\circ} \mathrm{C}$, which revealed that the drug was present as a crystalline form. Moreover, the diffraction patterns of HPMC (Fig. 7d) and HP- $\beta$-CD (Fig. 7e) displayed little crystalline peaks, and the melting points of HPMC (Fig. 8d) and HP- $\beta$-CD (Fig. 8e) were about $70.5{ }^{\circ} \mathrm{C}$ and $86.9{ }^{\circ} \mathrm{C}$, respectively, which illustrated that the both were existed in crystal state. The diffractogram of the physical mixture shown in Fig. $7 \mathrm{c}$ was the superimposed figures of each of the pure components with the peaks having a lower intensity, and the diffractogram consisted mostly of the HP- $\beta$-CD character, but some of the SLB characteristics remained. In addition, the DSC curve of the physical mixture

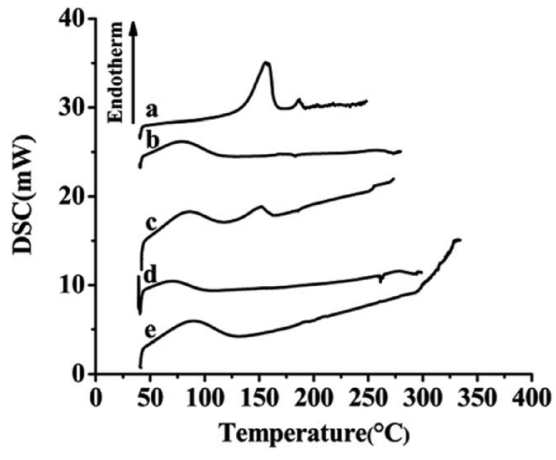

Fig. 8 DSC results of each sample. (a) Free SLB; (b) SLB nanoparticles; (c) physical mixture of SLB with excipients; (d) HPMC; (e) HP- $\beta-C D$.

(Fig. 8c) displayed two endothermic peaks at 85.3 and $152{ }^{\circ} \mathrm{C}$, corresponding to the melting peaks of HP- $\beta$-CD and SLB, which showed that the SLB existed as crystal in the physical mixture, and the characteristic peak of HPMC almost disappeared, this might be because the proportions of SLB and HP- $\beta$-CD in the physical mixture were larger, and the content of HPMC was small, resulting in the endothermic peak of HPMC was not obvious. However, the characteristic peaks of the SLB nanoparticles (Fig. 7b) were less than that of free SLB and the physical mixture, which indicated the crystallinity of the SLB nanoparticles decreased significantly, and the DSC curve of the SLB nanoparticles (Fig. 8b) only presented one endothermic melting peaks at $84.9^{\circ} \mathrm{C}$, corresponding to the melting peaks of HP- $\beta-C D$, and the characteristic peak of the SLB almost disappeared, consistent with the results of XRD, this illustrated that the SLB existed as amorphism in SLB nanoparticles. So, the SLB nanoparticles could have better dissolution and bioavailability.

\subsection{TG analyses}

The TG curves of the samples free SLB, SLB nanoparticles, physical mixture of SLB with excipients, HPMC and HP- $\beta$-CD were shown in Fig. 9. The free SLB (Fig. 9a) showed obviously thermal weight losses from $260.5^{\circ} \mathrm{C}$. The HPMC (Fig. 9d) and the HP- $\beta$-CD (Fig. 9e) began to loss weight from about $316.2^{\circ} \mathrm{C}$

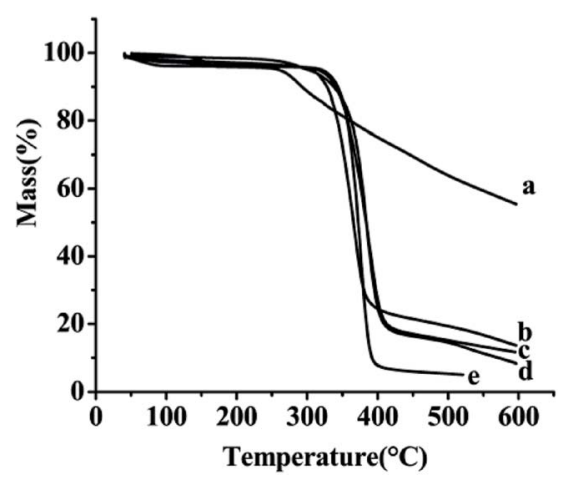

Fig. 9 TG results of each sample. (a) Free SLB; (b) SLB nanoparticles; (c) physical mixture of SLB with excipients; (d) HPMC; (e) HP- $\beta-C D$. 

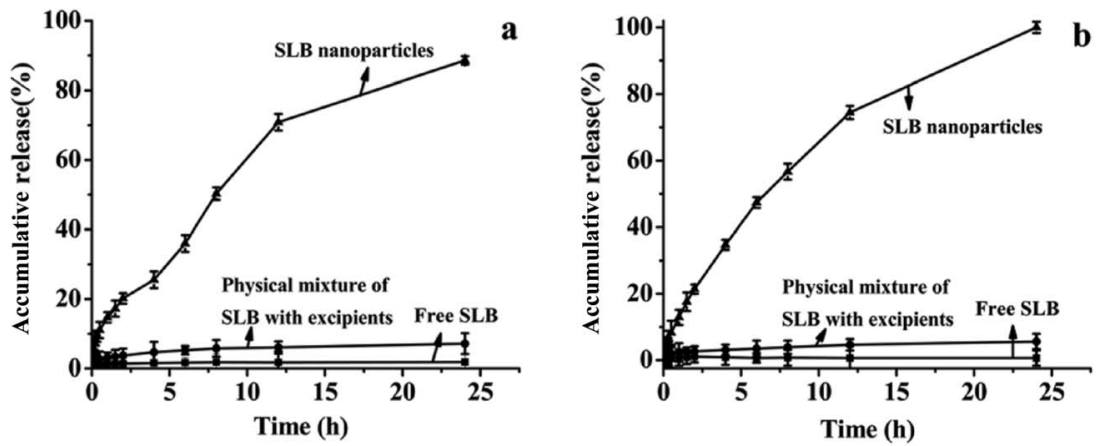

Fig. 10 The dissolution profiles of free SLB, physical mixture of SLB with excipients and SLB nanoparticles in artificial gastric juice (a) and artificial intestinal juice (b).

and $319.2^{\circ} \mathrm{C}$, respectively. The physical mixture (Fig. 9c) was observed to lose weight from about $328.4{ }^{\circ} \mathrm{C}$. However, the SLB nanoparticles (Fig. 9b) began to loss weight from $308.3^{\circ} \mathrm{C}$, and were more stable than the free SLB, which maybe because the HP- $\beta$-CD coated on the surface of the SLB and protected the SLB nanoparticles.

\subsection{Saturation solubility and dissolution}

Saturation solubility of free SLB, SLB nanoparticles and physical mixture of SLB with excipients at $37{ }^{\circ} \mathrm{C}$ was $0.09 \mathrm{mg} \mathrm{mL}{ }^{-1}$, $36.9 \mathrm{mg} \mathrm{mL}^{-1}$ and $1.07 \mathrm{mg} \mathrm{mL}^{-1}$ in AGJ (pH 1.2), respectively, and was $0.03 \mathrm{mg} \mathrm{mL}^{-1}, 59.71 \mathrm{mg} \mathrm{mL}^{-1}$ and $2.15 \mathrm{mg} \mathrm{mL}^{-1}$ in AIJ (pH 6.8), respectively. The saturation solubility of the physical mixture powder was higher than that of the free SLB, which demonstrated that the HP- $\beta$-CD was favorable for enhancing the solubility of SLB. But, the saturation solubility of the SLB nanoparticles was significantly higher than the others, which indicated that reducing the particle size down to the nanometer range can increase the saturation solubility of SLB. In addition, it has been reported that the silibinin nanoparticles were manufactured using the antisolvent precipitation with a syringe pump (APSP) method and the evaporative precipitation of nanosuspension (EPN) method. ${ }^{25}$ The equilibrium solubility of silibinin nanoparticles prepared was approximately $0.385 \mathrm{mg} \mathrm{mL} \mathrm{m}^{-1}$ (APSP) and $0.391 \mathrm{mg} \mathrm{mL}^{-1}$ (EPN), and was obviously lower than that of the SLB nanoparticles in this study. Therefore, in this paper, the SLB nanoparticles prepared was more propitious to improve the solubility of the SLB by the LAP method.

In vitro drug release profiles of free SLB, SLB nanoparticles and physical mixture of SLB with excipients were illustrated in Fig. 10 . As can be seen, $1.84 \%$ and $0.65 \%$ of the free SLB was dissolved in AGJ and AIJ in $24 \mathrm{~h}$. And the physical mixture was found to be dissolved $7.14 \%$ in AGJ and $5.63 \%$ in AIJ in $24 \mathrm{~h}$, and its dissolution rate was slightly higher than that of free SLB, this implied that the auxiliary material was favorable for the improvement of the solubility of SLB but it was not the key factor to enhance the solubility and the dissolution rate of SLB. While in the same period, SLB nanoparticles showed the significant increase in dissolution of SLB. About $88.6 \%$ and $100 \%$ of encapsulated SLB was dissolved in AGJ and AIJ, respectively. Therefore, at the same time, the dissolution rate of the SLB nanoparticles was significantly faster than that of free SLB, and was 48.2 times and 153.8 times that of the free SLB in AGJ and AIJ, respectively. The faster dissolution of SLB nanoparticles than free SLB can be attributed to its amorphous nature, smaller particle size and increased surface area. Moreover, the silibinin nanoparticles prepared by the APSP method and the EPN method, ${ }^{25}$ in vitro dissolution study, demonstrated more than $90 \%$ of cumulative dissolution within $90 \mathrm{~min}$ (aqueous solution, $0.1 \mathrm{M} \mathrm{HCl}$ solution and phosphate buffer ( $\mathrm{pH}$ 6.8) solution). It could be seen from the above analysis that the dissolution rate of the SLB nanoparticles in this study was slower than the silibinin nanoparticles prepared by the APSP and the EPN, this might be because the pretreatment of the samples were different in both studies, the silibinin nanoparticles obtained by the APSP and the EPN were directly put into the dissolution medium and studied, however, the SLB nanoparticles prepared in this study were placed into the dialysis bags and studied. In addition, the dissolution rate of the silibinin nanoparticles obtained by the APSP and the EPN was slightly faster than that of raw silibinin, and was about 1-2 times that of the raw silibinin in three different dissolution media (the raw silibinin achieving the maximum dissolution was about $80 \%$ at $90 \mathrm{~min}$ ). While, the dissolution rate of the SLB nanoparticles in this study was significantly faster than that of free SLB, and was 48.2 times and 153.8 times that of the free SLB in AGJ and AIJ, respectively. Therefore, under the same treatment conditions, the SLB nanoparticles in this study might have a faster dissolution rate compared with the silibinin nanoparticles obtained by the APSP and the EPN.

\subsection{Pharmacokinetic analysis and bioavailability}

The mean plasma concentration-time profiles for SLB nanoparticles and free SLB are presented in Fig. 11. The results demonstrated that both SLB nanoparticles and free SLB concentration-time curves could be fitted to the twocompartment model. The relevant pharmacokinetic parameters for the compartmental analysis are listed in Table 2. As shown in Fig. 11 and Table 2, the plasma concentration of rats treated with SLB nanoparticles was always higher than that of the rats treated with free SLB at the same dosage. The $C_{\max }$ value 


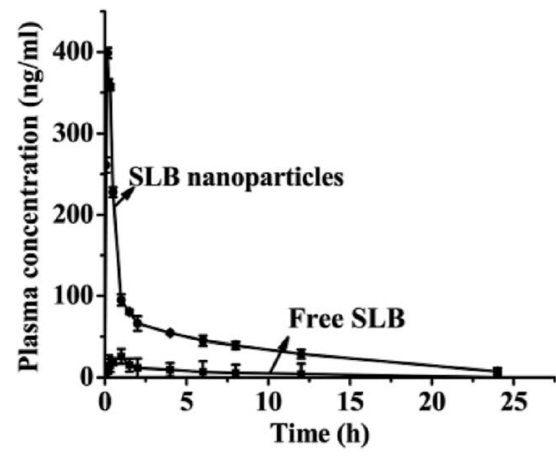

Fig. 11 The plasma concentration of free SLB and SLB nanoparticles.

Table 2 Pharmacokinetic parameters for SLB in rats after oral administration of free SLB and SLB nanoparticles

\begin{tabular}{llc}
$\begin{array}{l}\text { Pharmacokinetic } \\
\text { parameters }\end{array}$ & Free SLB & SLB nanoparticles \\
\hline$C_{\max }\left(\mathrm{ng} \mathrm{mL} \mathrm{mL}^{-1}\right)$ & 26.07 & 398.580 \\
$T_{\max }(\mathrm{h})$ & 1 & 0.167 \\
$t_{1 / 2}(\mathrm{~h})$ & 0.423 & 0.164 \\
MRT $(0-t)(\mathrm{h})$ & 4.413 & 6.33 \\
MRT $(0-\infty)(\mathrm{h})$ & 9.814 & 8.325 \\
AUC $(0-t)\left(\mathrm{ng} \mathrm{mL} \mathrm{mL}^{-1} \mathrm{~h}^{-1}\right)$ & 104.096 & 965.666 \\
AUC $(0-\infty)\left(\mathrm{ng} \mathrm{mL}^{-1} \mathrm{~h}^{-1}\right)$ & 149.124 & 1040.647
\end{tabular}

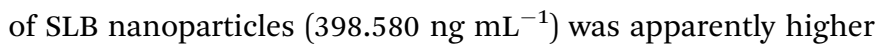
than that of free SLB $\left(26.070 \mathrm{ng} \mathrm{mL}^{-1}\right)$. The $T_{\max }$ in rats treated with SLB nanoparticles was also significantly shorter than those treated with free SLB. In addition, the AUC $(0 \rightarrow t)$ values of SLB

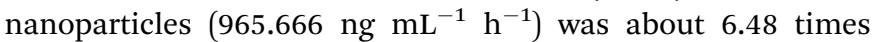
greater than that of free SLB $\left(149.124 \mathrm{ng} \mathrm{mL}^{-1} \mathrm{~h}^{-1}\right)$. And the half-life $\left(t_{1 / 2}\right)$ of SLB nanoparticles was $0.164 \mathrm{~h}$, which was also shorter than that of free SLB. Therefore, these results showed that the oral bioavailability of the SLB nanoparticles was improved significantly compared with the free SLB. Moreover, there was a related document reported that the silibinin nanoparticles (SB-NPs) were prepared using a nanoemulsification technique. ${ }^{26}$ In vivo pharmacokinetic study, the SB-NPs reached the maximum of the blood concentration

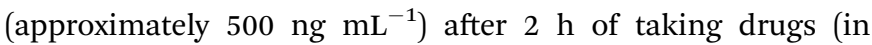
accordance with the dosage of $100 \mathrm{mg} \mathrm{kg}^{-1}$ ), however, the SLB nanoparticles prepared in this study reached the maximum of

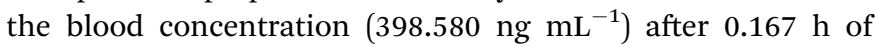
taking drugs (in accordance with the dosage of $50 \mathrm{mg} \mathrm{kg}^{-1}$ ). It could be seen from the above analysis that the plasma concentrations of the SLB nanoparticles in this study was slightly lower than the SB-NPs, this might be because the dosage of SLB was obviously different in both studies, but the SLB nanoparticles can be more quickly absorbed than the SB-NPs. In addition, it has been reported that the absolute oral bioavailability of pure silibinin in rats was calculated to be about $0.95 \% .{ }^{27}$ Based on comparative bioavailability data, the absolute bioavailability of SLB nanoparticles obtained in rats after oral

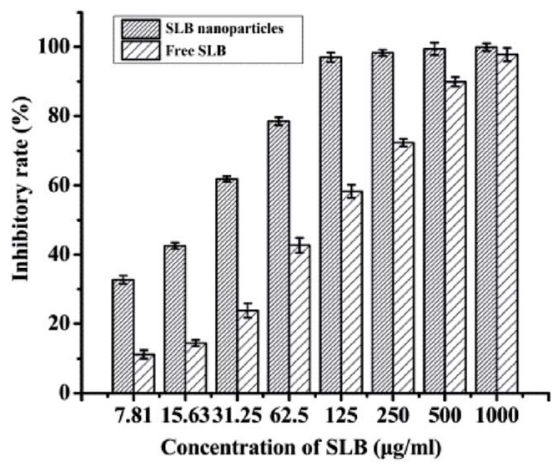

Fig. 12 Inhibitory rate of free SLB and SLB nanoparticles.

administration was calculated to be about $6.2 \%$ in this study. Therefore, the SLB nanoparticles obtained in this study was remarkably effective in improving the rate and extent of absorption of SLB, and can become a new oral drug formulation with high bioavailability and produce a better response for its clinical applications.

\subsection{Antitumor activity analysis}

SLB was a natural flavonoid that inhibited antiproliferative activities, but was not widely used because of its low bioavailability, the experiment prepared SLB nanoparticles by the LAP to improve the bioavailability of SLB, and applied the MTT assay to investigate the effect of drugs on the growth of HepG2 cells with different types of drugs (free SLB and SLB nanoparticles). The inhibitory rates of the samples were shown in Fig. 12. As can be seen from the figure, the inhibitory rate of all the samples increased with increasing concentration, but the SLB nanoparticles can inhibit cell proliferation more effectively than free SLB. In addition, the IC50 values of SLB nanoparticles and free SLB were $18.15 \mu \mathrm{g} \mathrm{mL}{ }^{-1}$ and $71.63 \mu \mathrm{g} \mathrm{mL}{ }^{-1}$, respectively, which also indicated that the SLB nanoparticles with high bioavailability had a higher inhibition to HepG2 cells by lower IC50 than that of free SLB.

\subsection{Residual ethanol content}

The SLB nanoparticles were analyzed for residual ethanol content using water as a solvent by the GC system. The detected results were shown in Fig. 13a and b. Fig. 13a showed the gas phase diagram of $10 \mathrm{mg} \mathrm{mL} \mathrm{mL}^{-1}$ water solution of the SLB nanoparticles. There was one solvent peak of ethanol, and its retention time was $1.83 \mathrm{~min}$. Fig. 13b showed the gas phase diagram of $0.05 \mathrm{mg} \mathrm{mL}^{-1}$ ethanol solution $\left(10 \mathrm{mg} \mathrm{mL}^{-1}\right.$ water solution of the SLB nanoparticles containing $0.5 \%$ ethanol). It can be concluded from this figure that the peak of ethanol in Fig. 13a was significantly smaller than that of ethanol in Fig. 13b. In addition, a regression equation, $Y=77726 x+216.3$ $\left(R^{2}=0.999\right)$, was obtained by GC detection, and the peak area was $Y$ and the ethanol concentration was $x$. The linear range of ethanol was $0.0782-100 \mu \mathrm{g} \mathrm{mL}^{-1}$. According to the regression equation, the residual ethanol content in SLB nanoparticles was about $1040 \mathrm{ppm}$. Therefore, these results revealed that the 

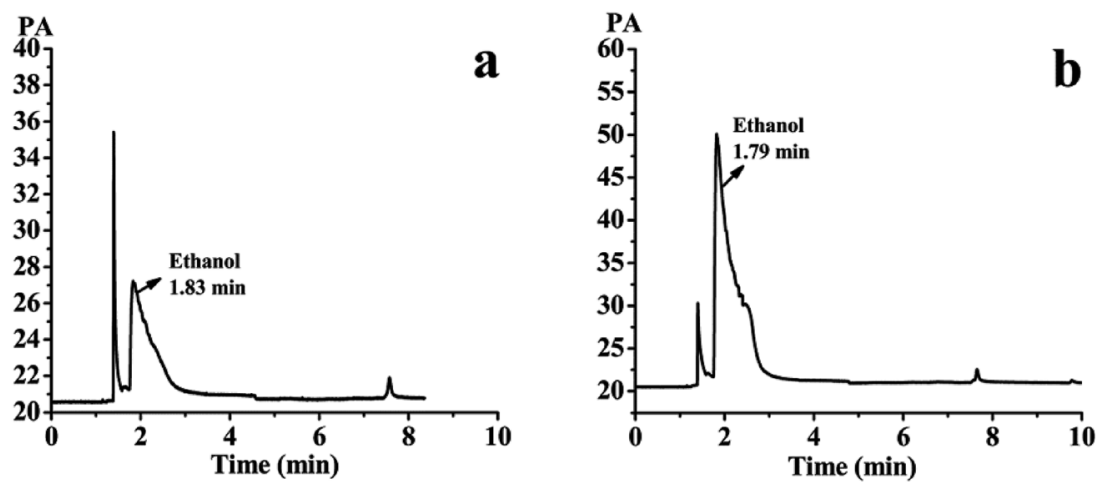

Fig. 13 (a) The gas phase diagram of $10 \mathrm{mg} \mathrm{mL}^{-1}$ water solution of the SLB nanoparticles; (b) the gas phase diagram of $0.05 \mathrm{mg} \mathrm{mL}^{-1}$ ethanol solution.

solvent residue in the SLB nanoparticles was conformed to ICH requirements and could be used for pharmaceutical.

\section{Conclusions}

The present study provides a simple and easy approach (the LAP method) to prepare the SLB nanoparticles, thereby improving its solubility and bioavailability. The single-factor experiments were used to optimize the procedure for the preparation of the SLB nanoparticles, and the optimum conditions obtained were: HPMC concentration $3 \mathrm{mg} \mathrm{mL} L^{-1}$, precipitation temperature $55{ }^{\circ} \mathrm{C}$, SLB concentration $35 \mathrm{mg} \mathrm{mL}{ }^{-1}$, antisolvent/solvent volume ratio 10 , dropping speed $1 \mathrm{~mL} \mathrm{~min}^{-1}$, stirring speed $800 \mathrm{rpm}$ and stirring time $5 \mathrm{~min}$. The SLB nanosuspension with a MPS of $132.3 \mathrm{~nm}$ was obtained under the optimum conditions. The HP- $\beta$-CD as a cryoprotectant (according to the mass ratio of SLB to HP- $\beta$-CD was $1: 7$ ) were added into the SLB nanosuspension and mixed evenly, finally the SLB nanoparticles was obtained by the vacuum freeze-drying machine. The physicochemical properties of the SLB nanoparticles were investigated, and the results showed that the SLB nanoparticles were transformed into an amorphous form without changing the chemical structure. In addition, the SLB nanoparticles had a higher solubility, and were about $36.9 \mathrm{mg} \mathrm{mL}^{-1}$ (free SLB was about $0.09 \mathrm{mg} \mathrm{mL}^{-1}$ ) in AGJ and were about $59.71 \mathrm{mg} \mathrm{mL}^{-1}$ (free SLB was about $0.03 \mathrm{mg} \mathrm{mL}^{-1}$ ) in AIJ. Meanwhile, the results of dissolution experiments in vitro showed that the dissolution rate of SLB nanoparticles were also obviously higher than that of free SLB, and was about 48.2 times and 153.8 times than that of free SLB in AGJ and AIJ. And the results of bioavailability study in rats indicated that the SLB nanoparticles had a higher and better bioavailability than free SLB. These results indicated that the small size of the amorphous SLB nanoparticles led to a significant boost of the solubility and the bioavailability. Furthermore, the SLB nanoparticles had a higher inhibition to HepG2 cells by lower IC50 than that of free SLB. And the residual ethanol of the SLB nanoparticles (1040 ppm) was less than the ICH limit for class 3 solvents of $5000 \mathrm{ppm}$ or $0.5 \%$ for solvents and could be used for pharmaceutical. Thus, the SLB nanoparticles can become a new oral drug formulation with high bioavailability and produce a better response for its clinical applications.

\section{Conflicts of interest}

There are no conflicts to declare.

\section{Acknowledgements}

The authors would also like to acknowledge the financial support from the National Natural Science Foundation of China (no. 21473023) and the Fundamental Research Funds of the Central Universities 2572016AA59.

\section{References}

1 J. M. Tan, G. Karthivashan, S. A. Gani, S. Fakurazi and M. Z. Hussein, Chem. Cent. J., 2016, 10, 81.

2 P. Mukhopadhyay, C.-L. Chen, J.-T. Chen, C.-M. Liang, M.-C. Tai, D.-W. Lu and Y.-H. Chen, PLoS One, 2017, 12, e0174971.

3 J. Q. Zhang, J. Liu, X. L. Li and B. R. Jasti, Drug Delivery, 2008, 14, 381-387.

4 I. Anestopoulos, A. Sfakianos, R. Franco, K. Chlichlia, M. Panayiotidis, D. Kroll and A. Pappa, Molecules, 2016, 22, 62.

5 E.-I. Pecheur, Y.-H. Chen, C.-L. Chen, D.-W. Lu, C.-M. Liang, M.-C. Tai and J.-T. Chen, PLoS One, 2016, 11, e0168765.

6 D. Pooja, D. J. Babu Bikkina, H. Kulhari, N. Nikhila, S. Chinde, Y. M. Raghavendra, B. Sreedhar and A. K. Tiwari, Int. J. Biol. Macromol., 2014, 69, 267-273.

7 X.-X. Zhu, Y.-H. Ding, Y. Wu, L.-Y. Qian, H. Zou and Q. He, Expert Rev. Clin. Pharmacol., 2016, 9, 1323-1330.

8 N. Rasenack and B. W. Müller, Pharm. Dev. Technol., 2004, 9, 1-13.

9 M. Gohulkumar, K. Gurushankar, N. Rajendra Prasad and N. Krishnakumar, Mater. Sci. Eng., C, 2014, 41, 274-282.

10 X. Cao, W. Deng, M. Fu, Y. Zhu, H. Liu, L. Wang, J. Zeng, Y. Wei, X. Xu and J. Yu, Eur. J. Pharm. Sci., 2013, 48, 64-71.

11 T. Zhao, D. Maniglio, J. Chen, B. Chen and C. Migliaresi, Chem. Phys. Lipids, 2016, 196, 81-88. 
12 S.-H. Kim, H.-J. Kim and S.-D. Yeo, J. Supercrit. Fluids, 2014, 85, 102-109.

13 X. Zhao, K. Song, S. Wang, Y. Zu, N. Li and X. Yu, Chem. Eng. Technol., 2013, 36, 33-42.

14 W. Zhe, J. F. Chen, Y. Le, Z. G. Shen and J. Yun, Ind. Eng. Chem. Res., 2007, 46, 4839-4845.

15 D. Yadav and N. Kumar, Int. J. Pharm., 2014, 477, 564-577.

16 Y. Zu, W. Sun, X. Zhao, W. Wang, Y. Li, Y. Ge, Y. Liu and K. Wang, Eur. J. Pharm. Sci., 2013, 53, 109-117.

17 A. Viçosa, J. J. Letourneau, F. Espitalier and M. I. Ré, J. Cryst. Growth, 2012, 342, 80-87.

18 S. Kim, W. K. Ng, Y. Dong, S. Das and R. Tan, J. Food Eng., 2012, 108, 37-42.

19 Y. Zu, W. Wu, X. Zhao, Y. Li, W. Wang, C. Zhong and Y. Zhang, Int. J. Pharm., 2014, 471, 366.

20 W.-Z. Zhu, J.-X. Wang, L. Shao, H.-X. Zhang, Q.-X. Zhang and J.-F. Chen, Int. J. Pharm., 2010, 395, 260-265.
21 J. Hecq, M. Deleers, D. Fanara, H. Vranckx and K. Amighi, Int. J. Pharm., 2005, 299, 167-177.

22 H. Terayama, K. Inada, H. Nakayama, S. Yasueda and K. Esumi, Colloids Surf., B, 2004, 39, 159-164.

23 Y. Zu, W. Wu, X. Zhao, Y. Li, W. Wang, C. Zhong, Y. Zhang and X. Zhao, Int. J. Pharm., 2014, 471, 366-376.

24 Y. Zu, W. Sun, X. Zhao, W. Wang, Y. Li, Y. Ge, Y. Liu and K. Wang, Eur. J. Pharm. Sci., 2014, 53, 109-117.

25 M. U. K. Sahibzada, A. Sadiq, S. Khan, H. S. Faidah, N. Ullah, M. Khurram, M. U. Amin and A. Haseeb, Drug Des., Dev. Ther., 2017, 11, 1453-1464.

26 C.-H. Liu, C.-C. Lin, W.-C. Hsu, C.-Y. Chung, C.-C. Lin, A. Jassey, S.-P. Chang, C.-J. Tai, C.-J. Tai, J. Shields, C. D. Richardson, M.-H. Yen, D. L. J. Tyrrell and L.-T. Lin, Gut, 2017, 66, 1853.

27 J. W. Wu, L. C. Lin, S. C. Hung, C. W. Chi and T. H. Tsai, J. Pharm. Biomed. Anal., 2007, 45, 635. 